TITLE:

\title{
Feasibility of externally activated self-repairing concrete with epoxy injection network and Cu-Al-Mn superelastic alloy reinforcing bars
}

\section{AUTHOR(S):}

Pareek, Sanjay; Shrestha, Kshitij C; Suzuki, Yusuke; Omori, Toshihiro; Kainuma, Ryosuke; Araki, Yoshikazu

\section{CITATION:}

Pareek, Sanjay ... [et al]. Feasibility of externally activated self-repairing concrete with epoxy injection network and Cu-Al-Mn superelastic alloy reinforcing bars. Smart Materials and Structures 2014, 23(10): 105027.

\section{ISSUE DATE:}

2014-09-16

\section{URL:}

http://hdl.handle.net/2433/198604

\section{RIGHT:}

This is an author-created, un-copyedited version of an article accepted for publication in Smart Materials and Structures. The publisher is not responsible for any errors or omissions in this version of the manuscript or any version derived from it. The Version of Record is available online at 10.1088/0964-1726/23/10/105027.; 許諾条件により本文ファ イルは2015-09-16に公開.; This is not the published version. Please cite only the published version.; この論文は出版社版 でありません。引用の際には出版社版をご確認ご利用ください。 
Manuscript submitted for possible publication in Smart Materials and Structures

Feasibility of externally activated self-repairing concrete with epoxy injection network and Cu-Al-Mn super-elastic alloy reinforcing bars

by S Pareek, K C Shrestha, Y Suzuki, T Omori, R Kainuma and Y Araki

1 Feasibility of externally activated self-repairing concrete with

\footnotetext{
Sanjay Pareek ${ }^{1}$, Kshitij C Shrestha ${ }^{2,3}$, Yusuke Suzuki ${ }^{4}$, Toshihiro Omori ${ }^{5}$, Ryosuke Kainuma ${ }^{5}$, and Yoshikazu Araki ${ }^{2}$

${ }^{1}$ Department of Architecture, College of Engineering, Nihon University, Koriyama 963-8642, Japan

2 Department of Architecture and Architectural Engineering, Graduate School of Engineering, Kyoto University, Kyoto 615-8540, Japan

${ }^{3}$ Department of Civil and Environmental Engineering, College of Engineering, University of Nevada, Reno, NV 89557, USA

${ }^{4}$ International Research Institute of Disaster Science, Tohoku University, Sendai 980-8579, Japan

${ }^{5}$ Department of Materials Science, Graduate School of Engineering, Tohoku University, Sendai 980-8579, Japan

E-mail: pareek@arch.ce.nihon-u.ac.jp and araki@archi.kyoto-u.ac.jp
}

\section{Abstract}

This paper studies the effectiveness of an externally activated self-repairing technique for concrete members with epoxy injection network and Cu-Al-Mn superelastic alloy (SEA) reinforcing bars (rebars). Compared to existing crack self-repairing and self-healing techniques, the epoxy injection network has the following strengths: (1) Different from the self-repairing methods using brittle containers or tubes for adhesives, the proposed self-repair process can be performed repeatedly and is feasible for onsite concrete casting. (2) Different from the autogenic self-healing techniques, full strength recovery can be achieved in a shorter time period without the necessity of water. This paper attempts to enhance the self-repairing capability of the epoxy injection network by reducing residual cracks by using cost-effective Cu-based SEA bars. The effectiveness of the present technique is examined using concrete beam specimens reinforced by 3 types of bars. The first specimen is reinforced by steel deformed bars, the second by steel threaded bars, and finally by SEA threaded rebars. The tests were performed with a 3 point cyclic loading with increasing amplitude. From the test results, effective self-repairing was confirmed for small deformation levels irrespective of the reinforcement types. Effective self-repairing was observed in the SEA reinforced specimen even under much larger deformations. Nonlinear finite element analysis was performed to confirm the experimental findings. 
Manuscript submitted for possible publication in Smart Materials and Structures

Feasibility of externally activated self-repairing concrete with epoxy injection network and Cu-Al-Mn super-elastic alloy reinforcing bars

by S Pareek, K C Shrestha, Y Suzuki, T Omori, R Kainuma and Y Araki

\section{Introduction}

Repair of damaged reinforced concrete (RC) structures in post-earthquake events is often difficult and in some situations impractical due to large residual deformations and/or excessive damages. Either repairing or demolishing of such structures involves considerable amount of cost and time. To address this issue, this paper proposes a self-repairing technique that can repair damage at a considerably lower cost within a much shorter time period. The proposed technique is capable of, first, deformation recovery and crack closing through application of superelastic alloy (SEA) reinforcing bars (rebars) [1], and secondly, self-repairing of cracks by injection of epoxy resin through networks of hollow ducts [2].

The self-repairing technique proposed by Pareek et al. [2] is an externally activated self-repairing technique, where the self-repairing process starts with injection of epoxy resin, followed by automatic sensing, processing, and actuating stages. Once epoxy resin is injected through the networks of hollow ducts with high pressure, the epoxy resin automatically locates the cracks that intersects through the networks. At this stage, the present technique does not need any sophisticated intelligent sensing technology or laborious process of detecting each crack by visual inspections. Once cracks are located, the processing and actuation functions are also performed automatically, where the epoxy resin penetrates into the detected cracks and hardens within the concrete to heal the cracks. According to RILEM Technical Committee 221-SHC [3,4], this technique falls under an autonomic self-healing process, and according to JCI Technical Committee JCI-TC-075B and JCI-TC-091A [4-6], it comes under the engineered self-repairing group of activated self-repairing system.

The self-repairing process is much easier to perform than conventional epoxy injection techniques $[7,8]$ because laborious process of detecting and repairing each crack is unnecessary. Since epoxy resin is injected with high pressure in the present technique, the strengthening effect is more reliable. Furthermore, we can avoid removal of interior walls and ceilings since injection is possible from any point. For instance, both the beam-column joints of a portal frame shown in Figure 1 can be repaired by injecting and ejecting epoxy resin only once from the left and right column bases, respectively. These characteristics lead to significant savings in time and cost required for the repair.

One of the strongest and most unique characteristics of the present self-repairing technique lies in its capability of performing self-repairing process repeatedly. Since excess epoxy in the networks is ejected out by air pressure after each cycle of self-repairing, the hollow ducts can be used again and again after an earthquake event or a certain elapsed time in the service life. This is a clear advantage compared to 
Manuscript submitted for possible publication in Smart Materials and Structures

Feasibility of externally activated self-repairing concrete with epoxy injection network and Cu-Al-Mn super-elastic alloy reinforcing bars

by S Pareek, K C Shrestha, Y Suzuki, T Omori, R Kainuma and Y Araki

other self-repairing techniques, wherein adhesives in brittle capsules or tubes are embedded in concrete [4,9,10-12]. Since such brittle containers can be used only once, repetitive repairing is very difficult in these techniques. Another characteristic of the present technique is the ease of concrete casting at construction sites, where concrete casting becomes very difficult if adhesives are embedded with brittle containers. In the present technique, in contrast, round smooth-surfaced bars (greased on surface for removal) are placed during concrete casting at the locations where hollow ducts are required. After concrete hardens, these bars are removed from the concrete to leave a hollow duct forming the network for epoxy injection.

The present technique is advantageous in comparison to natural or autogenic self-healing techniques that rely on existence of abundant water for rehydration of cement and crystallization to seal the cracks $[4,9,10]$. While these self-healing techniques have relatively low recovery of strength and requires a long self-healing time, the present technique is effective in a shorter time period ( 3 to 5 days) with almost full strength recovery. It can be applied under normal conditions and does not require external agents such as water etc.

The use of SEA rebars as reinforcing elements has been studied to reduce the damage of concrete [13-17]. In repairing concrete members after experiencing relatively large deformations, the use of conventional steel rebars would result in large residual cracks, which is difficult to repair. In the above studies, it has been demonstrated that the residual cracks can be reduced significantly by the use of SEA rebars even when concrete members are subjected to large deformations. The use of SEA rebars, however, does not repair the cracks of concrete. This led to the study of combining the use of SEAs with conventional epoxy injection [7] or inclusion of adhesives with brittle containers [17]. The repairing methods employed in these studies have the same difficulties mentioned earlier. In addition, these studies used Ni-Ti SEAs, whose high material cost and low machinability prohibit the wider use in practical situations.

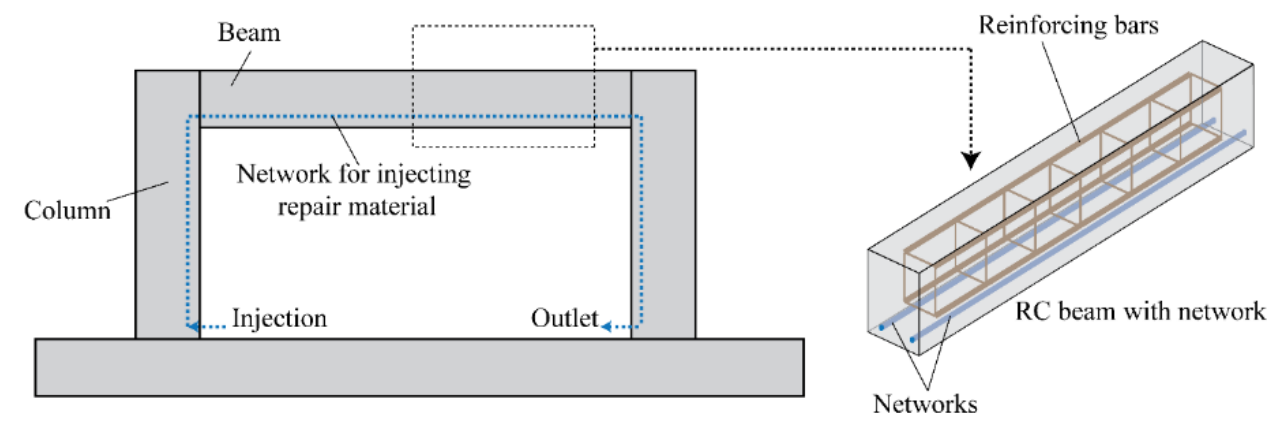

Figure 1. Schematic illustrations on the self-repairing technique. 
Manuscript submitted for possible publication in Smart Materials and Structures

Feasibility of externally activated self-repairing concrete with epoxy injection network and Cu-Al-Mn super-elastic alloy reinforcing bars

by S Pareek, K C Shrestha, Y Suzuki, T Omori, R Kainuma and Y Araki

1

To overcome the difficulties mentioned above, this paper proposes to combine the self-repairing technique proposed by Pareek et al. [2] and newly developed Cu-Al-Mn SEA rebars [18-20], which is superior in cost and machinability and has excellent superelasticity comparable to Ni-Ti SEAs. The present work can be viewed as an extension of the authors' previous study [1] on the use of Cu-Al-Mn SEA rebars for deformation recovery in RC beams, with an extension to self-repairing of concrete cracks by epoxy injection network. Comparison of 3 types of rebars is made and applicability of the self-repairing technique on each type of specimens is examined through cyclic loading experiments. Part of the experimental results reported here were presented in a conference paper by Shrestha et al. [21]. Numerical simulations and theoretical computations are performed to confirm and reinforce the experimental findings.

\section{Specimens and materials}

Figure 2 shows a concrete beam specimen used for the tests with the size of $80 \times 120 \times 420 \mathrm{~mm}$. Three different types of main bottom (tension side) rebars are used: (1) Steel deformed rebars (SD345), (2) Steel threaded rebars (SR235), and (3) Superelastic alloy (SEA) threaded rebars. Here, the prefixes SD and SR are used for steel reinforcement specified in JIS G 3112, which indicate steel deformed and round bars, respectively. The later numeric values in SD345 and SR235 represent the material's nominal (minimal) yield stress in MPa. The beam specimens are named correspondingly as SD-RC, ST-RC and SEA-RC specimens. The arrangement of main reinforcements, shear bars and dimensions of beams are shown in Figure 2. Additionally, there are two ducts network of $6 \mathrm{~mm}$ diameter located at $20 \mathrm{~mm}$ from the bottom of the specimen for the purpose of epoxy injection during the self-repairing process.
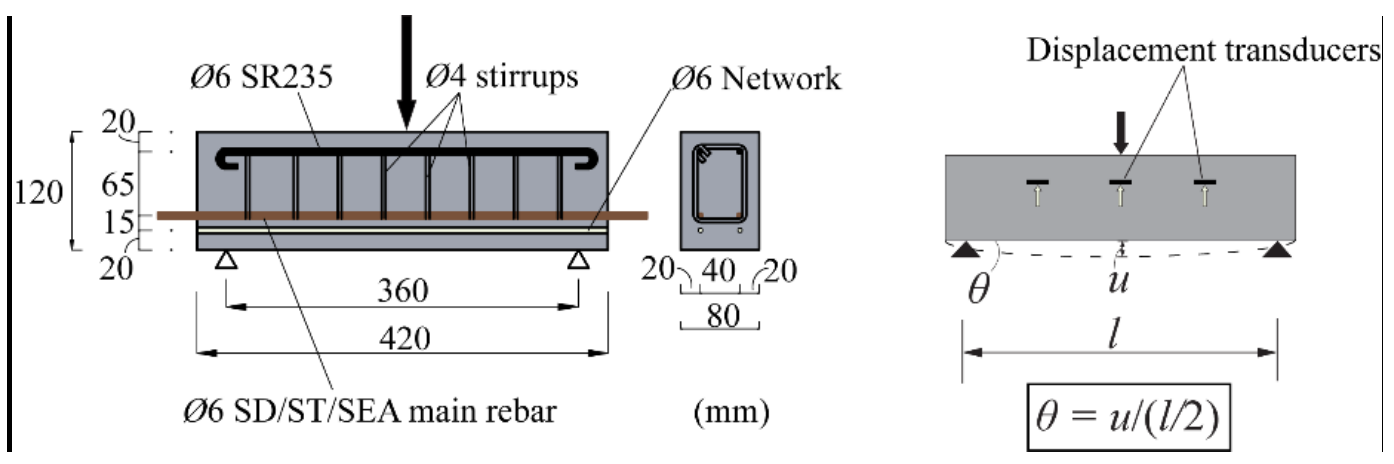

Figure 2. RC Specimen detail and test set-up. 
Manuscript submitted for possible publication in Smart Materials and Structures

Feasibility of externally activated self-repairing concrete with epoxy injection network and Cu-Al-Mn super-elastic alloy reinforcing bars

by S Pareek, K C Shrestha, Y Suzuki, T Omori, R Kainuma and Y Araki

\subsection{Concrete}

The composition of cement (ordinary Portland), aggregate, and water for the mortar is 1:4.4:0.6. Here, the ratio of aggregates with particle size less than $2.5 \mathrm{~mm}$ and those between 2.5 and $5.0 \mathrm{~mm}$ was $1: 2$. Six cylindrical test specimens of the concrete, with a diameter of $50 \mathrm{~mm}$ and a height of $100 \mathrm{~mm}$, are prepared for compressive strength tests. Here, the 28-day cured average compressive strength was 24.7MPa with the standard deviation of 1.8MPa.

\subsection{Reinforcing bars}

Three types of bottom (tension side) rebars are used. For SD-RC beams, 6mm diameter SD345 bars are used. For ST-RC beams, threaded 6mm diameter SR235 steel bars are used. For SEA-RC beams, threaded 6mm diameter SEA rebars are used as bottom reinforcements. The rebars at the compression (upper) side and the stirrups are $6 \mathrm{~mm}$ and $4 \mathrm{~mm}$ diameter round SR235 steel bars respectively. Figure 3 shows the results of the tensile tests of the corresponding rebar samples. Table 1 gives the mechanical properties for the SD, ST and SEA rebars used for the experiments. Here, the elastic modulus and the yield, or transformation, stress for the rebar is computed as the $0.2 \%$ offset stress. Note that the test results presented in Figure 3 and Table 1 for the SEA rebar is given for a representative SEA rebar sample for each type of rebar. It was found that there is small variability in mechanical characteristics for different samples of Cu-Al-Mn SEA rebars as reported by Shrestha et al. [1]. All the rebars used have either a deformed or threaded surface, hence they offer good bond behavior with the surrounding concrete. It should be noted that the strength characteristics of the SD, ST and SEA rebars are different as shown in Figure 3 and Table 1. It is essentially impossible to prepare SD and ST rebars which have the same values for diameter, stiffness, and strength as the SEA rebar. Here, the authors chose to make the diameter of rebars same, which has an important effect on the crack width.

\subsection{Epoxy resin}

Epoxy resin is used as a self-repairing agent and injected through the network which is a hollow duct. In this study, 2 types of epoxy resin are used for this purpose, having differences in their viscosity and thixotropic index. Viscosity measures the material's resistance to flow in static condition and thixotropic index gives its resistance to flow in dynamic condition. Here, L-epoxy has lower viscosity and thixotropic index as compared to M-epoxy. The properties of the epoxy resins are given in Table 2. Here, 
Manuscript submitted for possible publication in Smart Materials and Structures

Feasibility of externally activated self-repairing concrete with epoxy injection network and Cu-Al-Mn super-elastic alloy reinforcing bars

by S Pareek, K C Shrestha, Y Suzuki, T Omori, R Kainuma and Y Araki

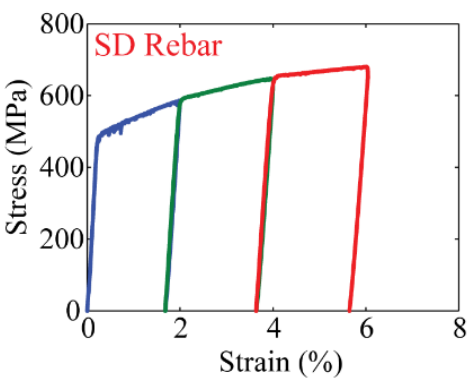

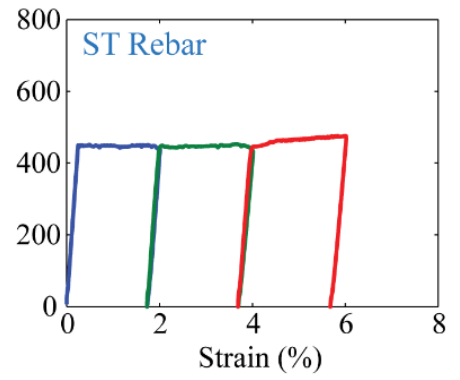

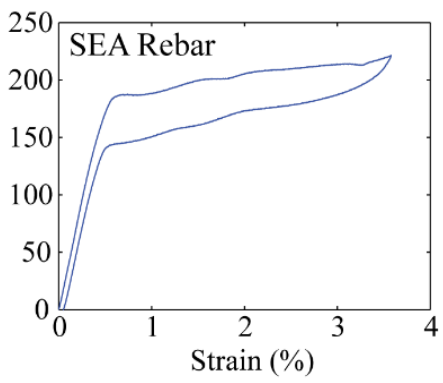

Figure 3. Cyclic tensile test results on SD, ST and SEA rebars.

Table 1 Mechanical properties of reinforcing bars

\begin{tabular}{ccccc}
\hline \multirow{2}{*}{ Reinforcing bar type } & $\begin{array}{c}\text { Elastic modulus, } \\
\text { GPa }\end{array}$ & $\begin{array}{c}\text { Transformation stress, } \\
\text { MPa }\end{array}$ & $\begin{array}{c}\text { Recovery strain, } \\
\%\end{array}$ & $\begin{array}{c}\text { Fracture strain, } \\
\%\end{array}$ \\
\hline SD & 190 & 453 & -- & $18 \sim 20$ \\
ST & 185 & 430 & -- & $18 \sim 20$ \\
SEA & 29 & 180 & 8 & 18 \\
\hline
\end{tabular}

17

Table 2 Characteristics of epoxy resin

\begin{tabular}{ccccc}
\hline Epoxy resin type & Hardening mechanism & Thixotropic index & $\begin{array}{c}\text { Specific density } \\
\mathrm{g} / \mathrm{cm}^{3}, 23^{\circ} \mathrm{C}\end{array}$ & $\begin{array}{c}\text { Viscosity } \\
\mathrm{mPa} . \mathrm{s}, 23^{\circ} \mathrm{C}\end{array}$ \\
\hline $\mathrm{L}$ & Moisture sensitive & 1.0 & 1.15 & 150 \\
$\mathrm{M}$ & Moisture sensitive & 2.2 & 1.07 & 1900 \\
\hline
\end{tabular}


Manuscript submitted for possible publication in Smart Materials and Structures

Feasibility of externally activated self-repairing concrete with epoxy injection network and Cu-Al-Mn super-elastic alloy reinforcing bars

by S Pareek, K C Shrestha, Y Suzuki, T Omori, R Kainuma and Y Araki

\subsection{Test Plan-1: Effectiveness of SEA rebars for crack closing of RC beams}

Test Plan-1 involves repeated cyclic loading on one set of each type of RC beam specimens, namely, SD-RC1, ST-RC1 and SEA-RC1 without application of any self-repairing, as illustrated in Figure 4. The repeated cyclic loading is performed in an increasing order of displacement amplitude with rotation angles of $\theta_{1}=1 / 150 \mathrm{rad}, \theta_{2}=1 / 75 \mathrm{rad}$ and $\theta_{3}=1 / 40 \mathrm{rad}$, where the rotation angle $\theta$ are computed as shown in Figure 2. These three rotation angle values are selected based on several preliminary tests to simulate the following crack widths:

(a) Less than 0.3mm; Structural crack limit for RC structures according to Architectural Institute of Japan (AIJ) RC standards [23].

(b) From $0.3 \mathrm{~mm}$ to $0.5 \mathrm{~mm}$; To find out the effectiveness of SEA rebars for crack recovery above AIJ standards.

(c) From 0.5 to 5mm; To find out the effectiveness of SEA rebars for crack recovery at the ultimate state of RC structures.

The purposes of these tests are to study the crack recovery properties of each type of specimens and to examine the effectiveness of SEA-RC beam over RC beams with other steel rebar types. Further, the crack widths observed for the test specimens in Test Plan-1 forms the basis for planning Test-Plan-2 to decide the type of epoxy to be used in Test-Plan-2

\subsection{Test Plan-2: Effectiveness of self-repairing (SR) network system on crack healing}

Test Plan-2 studies the feasibility of the present self-repairing technique on each type of RC beam specimen under 3 different deformation levels (rotation level $\theta_{1}=1 / 150 \mathrm{rad}, \theta_{2}=1 / 75 \mathrm{rad}$, and $\theta_{3}=1 / 40 \mathrm{rad}$ ). The complete work flow adopted in loading, repairing, and reloading is schematically illustrated in Figure 5. The process involves the first phase of loading on RC beam, resulting in residual cracks after the release of load. This step is subsequently followed by epoxy injection to the hollow duct network at room temperature. Crack widths, not exceeding $0.4 \mathrm{~mm}$, are healed with L-Epoxy resin [22] and the ones exceeding this value are healed with combination of both $\mathrm{L}$ and M-Epoxy resins, where application involves first L-Epoxy resin injection and afterwards M-Epoxy resin injection. The injection process is followed by ejection of excess epoxy from the duct by blowing pressurized air through the duct, which enables repetitive self-repairing. The epoxy resin ejection is followed by accelerated curing of the specimens for 3 days at $40^{\circ} \mathrm{C}$ and $60 \%$ relative humidity (RH). After 3 days of accelerated curing, the 
Manuscript submitted for possible publication in Smart Materials and Structures

Feasibility of externally activated self-repairing concrete with epoxy injection network and Cu-Al-Mn super-elastic alloy reinforcing bars

by S Pareek, K C Shrestha, Y Suzuki, T Omori, R Kainuma and Y Araki

1 degree of self-repairing performed on the respective repaired specimens is measured by using an

2 ultrasonic pulse velocity testing instrument Pundit Lab+ of Proceq Co.. The rate of crack self-repairing

3 is computed by the observed transit time at 6 different positions in the tested beam specimen. It should

4 be noted that this ultrasonic pulse test is performed at 3 different stages, first, at the specimen after

5 curing and unloaded state, second, at the cracked state after first loading phase and third, after the

6 self-repairing just before the second reloading phase as illustrated in Figure 6. The self-repaired

7 specimen is further reloaded in its second phase of loading, where the effectiveness of the self-repairing

8 is determined by either origination of new cracks or reopening of the previously formed cracks.

9 Three sets of SEA-RC beam specimens are tested, SEA-SR1, SEA-SR2 and SEA-SR3, where SR 10 stands for the self-repairing. Self-repairing capability of the SEA-SR specimens are examined at all 3

11 different load levels. On the other hand, SD-RC and ST-RC beam specimens showed residual crack

12 width exceeding $3 \mathrm{~mm}$, when loaded at the deformation level with rotation angle $\theta_{3}$ in the preliminary

13 tests. For this reason, self-repairing is done for only 2 sets of SD-SR and ST-SR specimens, loaded at the

14 first 2 deformation load levels $\left(\theta_{1}\right.$ and $\left.\theta_{2}\right)$. The details on the loading protocol adopted for each of the specimens are presented in Figure 7.

16

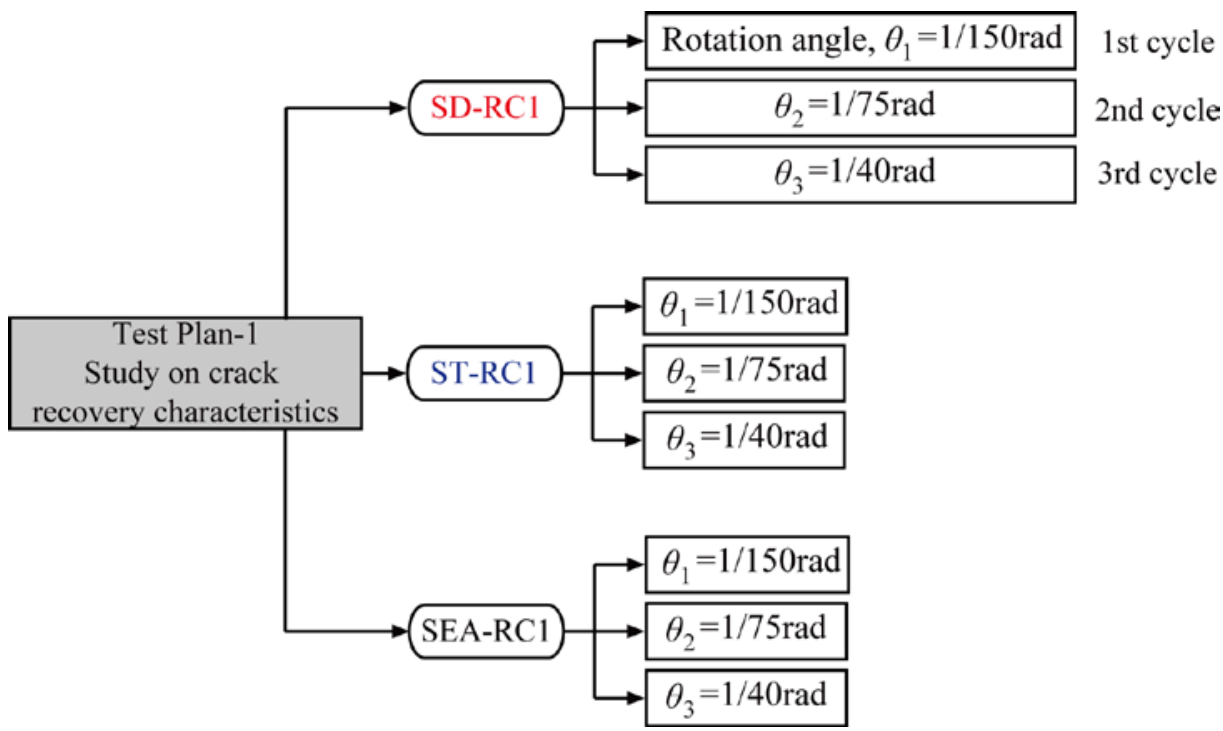

Figure 4. Details on Test Plan-1. 
Manuscript submitted for possible publication in Smart Materials and Structures

Feasibility of externally activated self-repairing concrete with epoxy injection network and Cu-Al-Mn super-elastic alloy reinforcing bars

by S Pareek, K C Shrestha, Y Suzuki, T Omori, R Kainuma and Y Araki

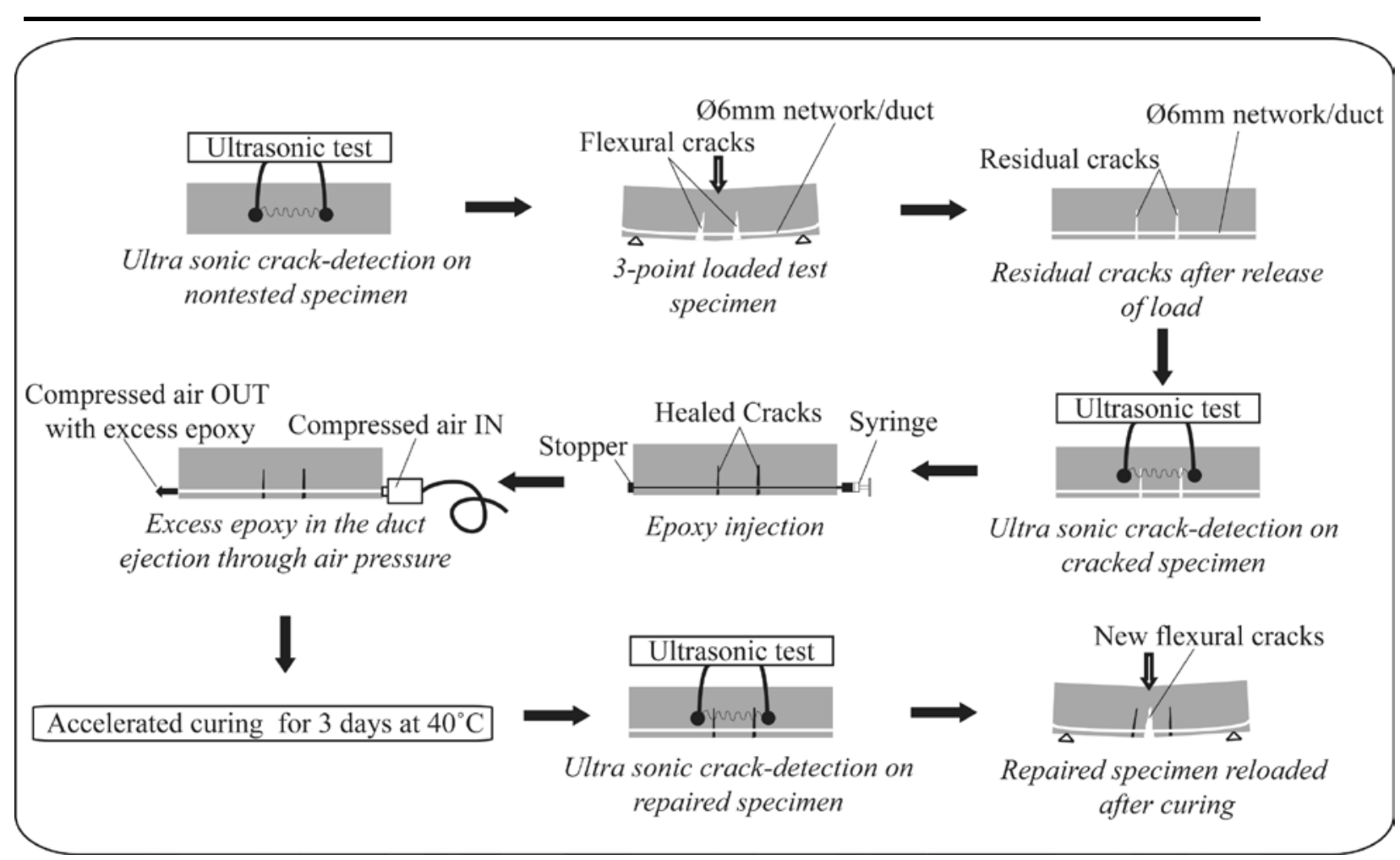

Figure 5. Work-flow for the present study on the externally activated self-repair network system (Test Plan-2).

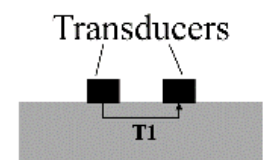

Un-tested specimen

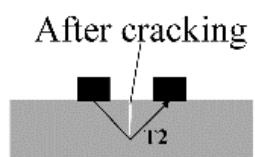

Tested specimen after 1 st cycle of loading

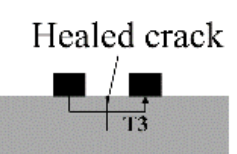

Specimen after epoxy injection and curing

$$
\text { Rate of crack healing }=\frac{\mathrm{T} 2-\mathrm{T} 3}{\mathrm{~T} 2-\mathrm{T} 1} \times 100
$$

Figure 6. Transit time detection using ultrasonic tester for computation of rate of crack self-repairing.

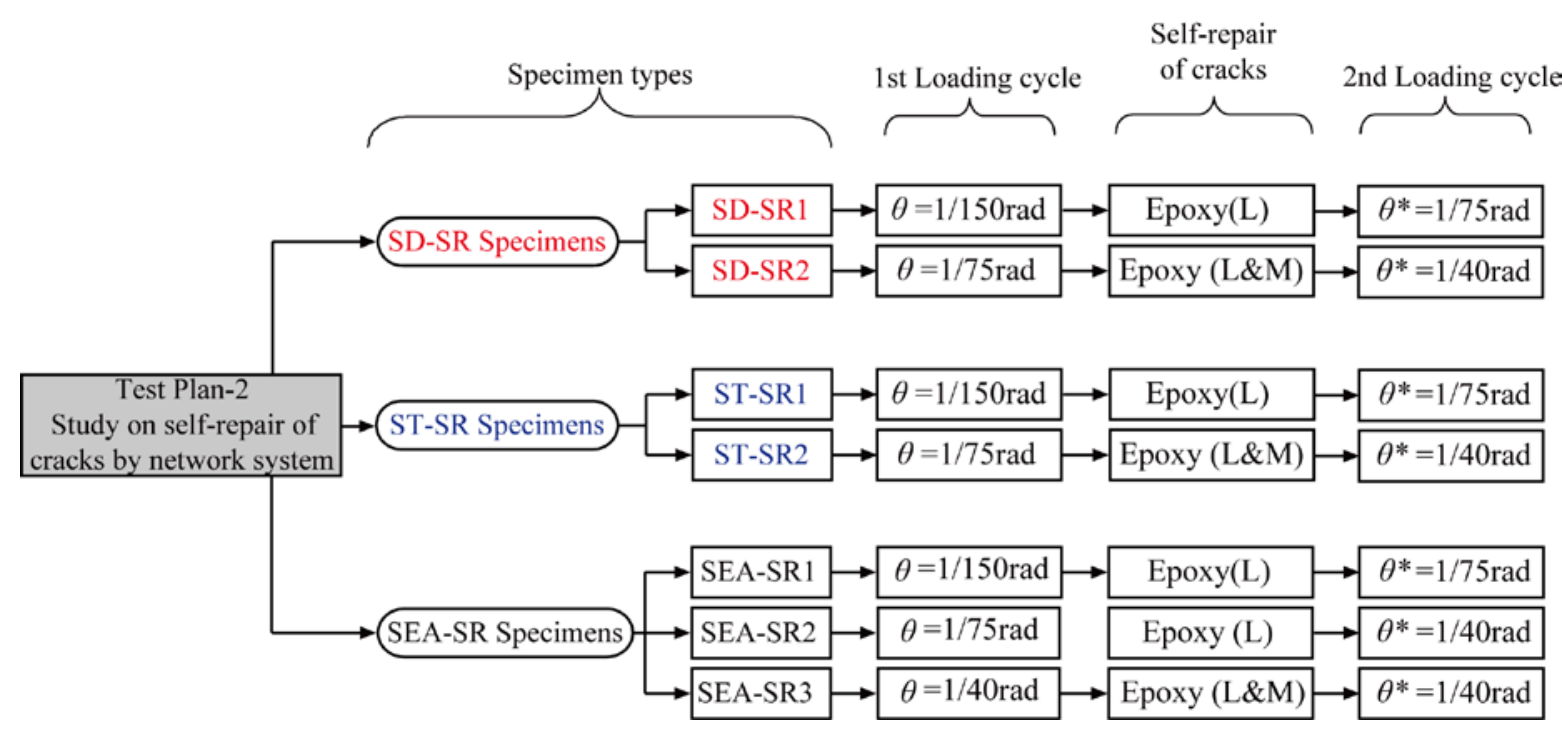

Figure 7. Details on Test Plan-2. 
Manuscript submitted for possible publication in Smart Materials and Structures

Feasibility of externally activated self-repairing concrete with epoxy injection network and Cu-Al-Mn super-elastic alloy reinforcing bars

by S Pareek, K C Shrestha, Y Suzuki, T Omori, R Kainuma and Y Araki

1

\section{Finite element (FE) modeling}

\subsection{Model generation}

Several models were proposed to predict the response of concrete members reinforced by SEA bars [24,25]. In this paper, 2 dimensional finite element (FE) models are generated and analyzed using the general purpose FE program DIANA [26]. For the FE representation, a RC member is discretized with a rectangular grid of nodes. Concrete is represented by quadrilateral smeared-crack elements. Reinforcing bars are represented by smeared overlay or by discrete truss elements. The details of the elements used are described below:

4.1.1 Concrete. In this study, 8-node quadrilateral isoparametric plane stress element is adopted for representing concrete elements. Meshing is performed as shown in Figure 8 with the mesh size ranging from 4 to $5 \mathrm{~mm}$.

Concrete is modeled with constitutive models based on total strain rotating crack models, which describe the tensile and compressive behavior of a material with one stress-strain relationship [27]. Details and applicability of the model were reported by Shrestha et al. [1]. Here, the mean value of the compression strength is $25 \mathrm{MPa}$. The value of concrete tensile strength adopted is $2 \mathrm{MPa}$.

4.1.2 Reinforcing bar. For the SD and ST reinforced beam FE models, both the axial and shear steel rebars are represented by regular embedded reinforcement elements smeared within concrete elements. A perfect bond is assumed between the reinforcement and concrete elements. Monti-Nuti model [28] is employed in this study to represent the hysteretic stress-strain behavior of reinforcing steel as shown in Figure 9. Memory hardening rule is chosen for each load reversal. Material parameters adopted for SD and ST rebars are presented in Table 3. The yield stress, $f_{\mathrm{yst}}$, of 500MPa for SD rebar and 400MPa for ST rebar are adopted with Young's modulus $E_{\text {st }}=210 \mathrm{GPa}$ and other parameter values for both the rebars are assumed based on the test results and values proposed by Monti and Nuti illustrated in Table 3. Constitutive law and its details are reported in Monti and Nuti [28] and DIANA [26]. 
Manuscript submitted for possible publication in Smart Materials and Structures

Feasibility of externally activated self-repairing concrete with epoxy injection network and Cu-Al-Mn super-elastic alloy reinforcing bars

by S Pareek, K C Shrestha, Y Suzuki, T Omori, R Kainuma and Y Araki

\begin{tabular}{|c|c|c|c|c|c|c|c|}
\hline \multirow{2}{*}{$\begin{array}{l}\text { Rebar } \\
\text { type }\end{array}$} & \multirow{2}{*}{$\begin{array}{c}\text { Yield } \\
\text { stress, } \\
(\mathrm{MPa})\end{array}$} & \multirow{2}{*}{$\begin{array}{c}\text { Elastic } \\
\text { modulus, } \\
E(\mathrm{GPa})\end{array}$} & \multirow{2}{*}{$\begin{array}{l}\text { Hardening } \\
\text { ratio, } b^{0}\end{array}$} & \multirow{2}{*}{$\begin{array}{c}\text { Curvature } \\
\text { parameter, } \\
R^{0}\end{array}$} & \multicolumn{2}{|c|}{ Material constants } & \multirow{2}{*}{$\begin{array}{c}\text { Weighing } \\
\text { coefficient, } P\end{array}$} \\
\hline & & & & & $A_{1}$ & $A_{2}$ & \\
\hline SD & 500 & 210 & 0.02 & 22 & 18.5 & 0.0001 & 0.5 \\
\hline ST & 400 & 210 & 0.005 & 22 & 18.5 & 0.0001 & 0.5 \\
\hline
\end{tabular}

Figure 8. FE model discretization.

Table 3 Material parameters of SD and ST rebars adopted for FE model
5

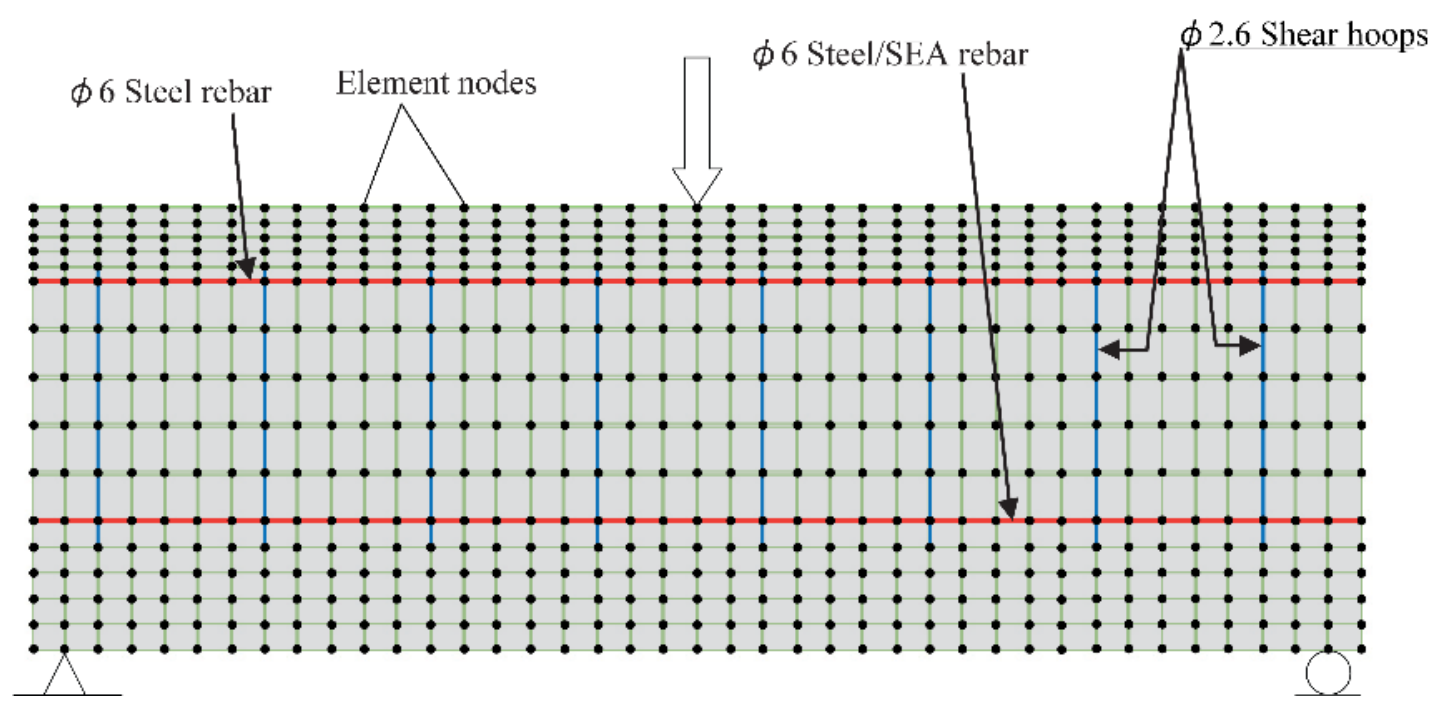

SEA rebars are represented by truss elements and their flag shaped hysteresis is realized by a user-supplied subroutine USRMAT. The subroutine is based on a rate-independent piecewise linear flag-shaped hysteretic model. Such model was used by Christopoulos et al. [29] and Seo and Sause [30] in the studies involving self-centering systems. Here the residual strain, being negligible in the SEA rebar as shown in Figure 3, is not taken into account in numerical modeling. The piecewise linear flag-shaped hysteretic model shown in Figure 10 can describe the stress-strain relationship of superelastic alloy with 5 material parameters (values adopted shown in parenthesis): austenitic elastic modulus $E_{1}$ (25GPa), post-yield stiffness coefficient $\alpha$ (0.03), strain at the start of transformation or yield $\varepsilon_{1}(0.008)$, energy dissipation coefficient $\psi(0.25)$, and transformation finish strain $\varepsilon_{2}(0.075)$. The martensitic elastic modulus is assumed to be the same as $E_{1}$. These values adopted here are selected based on the variability in the stress-strain curves of SEA rebars [1] and do not necessarily correspond to the values presented in Table 1.

Rebars at the compression (upper) side for all the FE model types are represented by truss elements assuming a perfectly plastic yielding with yield stress, $f_{\text {yst }}$, of $275 \mathrm{MPa}$ and Young's modulus $E_{\mathrm{st}}=$ 
Manuscript submitted for possible publication in Smart Materials and Structures

Feasibility of externally activated self-repairing concrete with epoxy injection network and Cu-Al-Mn super-elastic alloy reinforcing bars

by S Pareek, K C Shrestha, Y Suzuki, T Omori, R Kainuma and Y Araki

210GPa. It should be noted that this relatively lower value for the compression rebars are determined in a trial and error manner so that the numerical results, especially residual deformation, can be effectively replicated. Also note that the response is sensitive not only to the yield stress but also to the mesh sizes of the concrete and the rebar elements.

In this paper, the effect of epoxy resin on the stiffness of the whole concrete beam is assumed to be negligible. This is because the crack width, where epoxy resin is injected, is very thin. In most cases, the crack width is less than $0.5 \mathrm{~mm}$. The effect of epoxy resin on the strength of the concrete beam is also assumed to be negligible. This is because the strength of the whole beam is determined by the strength of concrete, which is lower than the bond strength of epoxy, as observed in the experiments in this paper. One of the motivations for performing the FE analysis is to examine whether these assumptions result in large deviations of results or not.
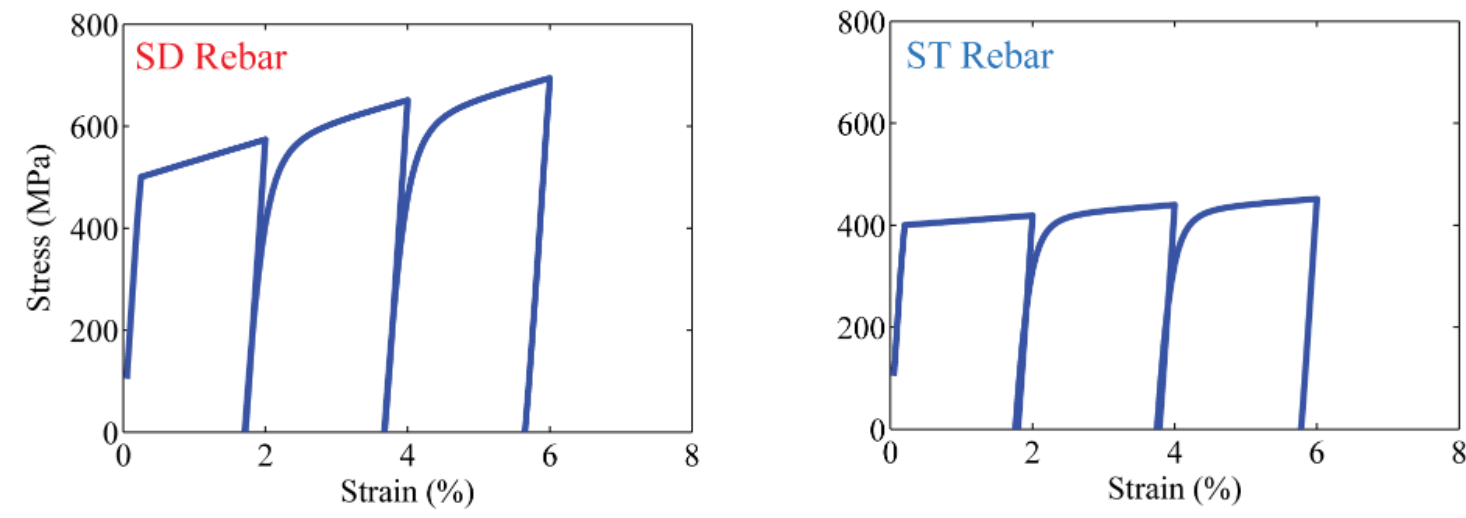

Figure 9. Constitutive model hysteresis for SD and ST rebars.
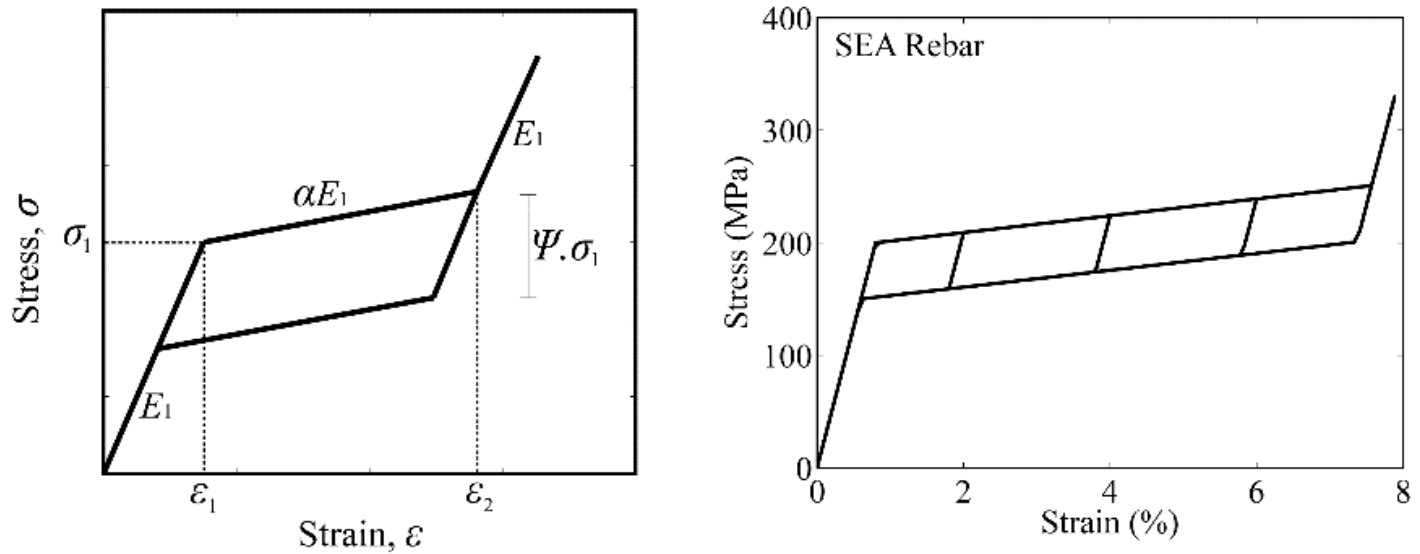

Figure 10. Constitutive model hysteresis for SEA rebar. 
Manuscript submitted for possible publication in Smart Materials and Structures

Feasibility of externally activated self-repairing concrete with epoxy injection network and Cu-Al-Mn super-elastic alloy reinforcing bars

by S Pareek, K C Shrestha, Y Suzuki, T Omori, R Kainuma and Y Araki

\section{Results and discussions}

5.1 Test Plan-1: Figures 11 and 12 show the results for the cyclic loading performed for SD-RC1, ST-RC1 and SEA-RC1 specimens in Test Plan-1. The value of the observed resisting force varied with the type of rebars used in the specimens, as each of them has a unique strength and deformation characteristic, as illustrated in Figure 3.

After initial cracking and subsequent yielding of rebars, SD-RC1 and ST-RC1 specimens started to show large residual deformations and residual cracks upon unloading mainly contributed by plastic deformations of the bottom (tension) rebars. SEA-RC1 specimen, on the other hand, showed an almost flag-shaped hysteresis with a remarkable deformation recovery and significant enhancement in crack closing capability. The force-deformation hysteresis is also compared with the FE results. The numerical results are in good agreement with the test results. It should be noted that there is some discrepancy for the first loading cycle, where the FE results showed comparatively stiff response. This is possibly due to unevenness of the concrete beam top surface where the loading plate was placed. The residual rotation for SEA-RC1 specimen is due to the plastic yielding of the steel rebars in the compression side. This was confirmed with the FE results, where no residual rotation was observed when fully elastic response of the upper reinforcing bars was assumed.

For the SEA-RC FE model, the top steel rebar showed yielding for the third loading cycle with $\theta_{3}=1 / 40$ rad. Such residual rotation for SEA-RC specimen can be reduced using SEA rebar in the compression side as well [1]. The residual rotation predicted by the FE models matched closely for SD-RC1 and ST-RC1 specimens. However, SEA-RC FE model's prediction deviated slightly from the test results. The response of SEA-RC FE model at larger displacement levels was also governed by yielding of compression steel rebars. It was found that such response governed by yielding of compression steel rebar was difficult to simulate because the result was sensitive not only to the yield stress value for compression steel but also to the mesh sizes and bonding conditions between the concrete and the upper rebar elements.

Furthermore, theoretical computation for the yield load, $F_{\mathrm{R}}^{\mathrm{Y}}$ and the maximum capacity load, $F_{\mathrm{R}}^{\mathrm{C}}$ are also made by neglecting the strength contribution by concrete elements. Here, the yield and maximum capacity stress values for the SD rebar are taken to be 450MPa (for $F_{\mathrm{R}}^{\mathrm{Y}}$ ) and 620MPa (for $F_{\mathrm{R}}^{\mathrm{C}}$ ) 
Manuscript submitted for possible publication in Smart Materials and Structures

Feasibility of externally activated self-repairing concrete with epoxy injection network and Cu-Al-Mn super-elastic alloy reinforcing bars

by S Pareek, K C Shrestha, Y Suzuki, T Omori, R Kainuma and Y Araki

respectively. For the ST rebar, the following values are taken 430MPa (for $F_{\mathrm{R}}^{\mathrm{Y}}$ ) and 500MPa (for $F_{\mathrm{R}}^{\mathrm{C}}$ ), and for the SEA rebar the values adopted are 200MPa (for $F_{\mathrm{R}}^{\mathrm{Y}}$ ) and 400MPa (for $F_{\mathrm{R}}^{\mathrm{C}}$ ). The values adopted are based on the average values for each rebar obtained through tensile tests done as illustrated in Figure 3. Both the test and numerical results are relatively close to the theoretically computed loads.

Figure 12 shows the comparison on the crack widths for each type of the specimens, where cracks were measured using a crack scale. Figure 13 shows the pictures of the cracked specimens at the instants of the loaded and unloaded positions. Large residual crack widths, more than 3mm, were seen for SD-RC1 and ST-RC1 specimens, for the deformation level of $\theta_{3}=1 / 40 \mathrm{rad}$. SEA-RC1 specimen demonstrated strong capability of crack closing with residual crack widths within $0.5 \mathrm{~mm}$, even for this maximum deformation level.

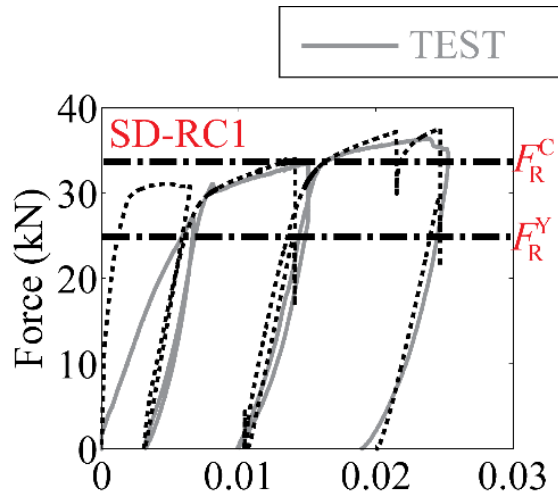
(1) 16

(1) 
Manuscript submitted for possible publication in Smart Materials and Structures

Feasibility of externally activated self-repairing concrete with epoxy injection network and Cu-Al-Mn super-elastic alloy reinforcing bars

by S Pareek, K C Shrestha, Y Suzuki, T Omori, R Kainuma and Y Araki

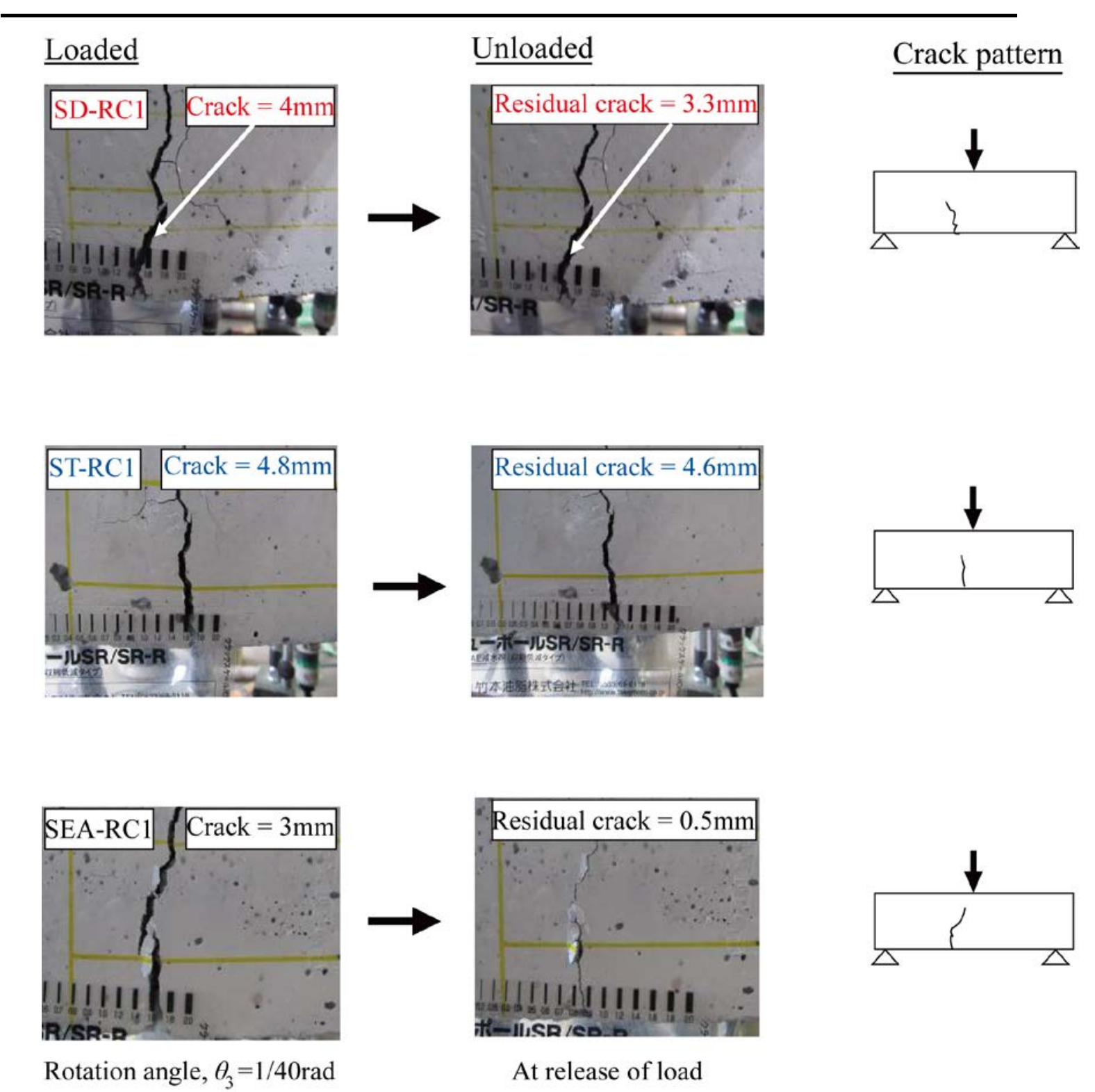

Figure 13. Observations on crack recovery for SD-RC1, ST-RC1 and SEA-RC1 specimens.

$4 \quad 5.2$ Test Plan-2: The details on the loading amplitudes, corresponding residual crack widths and subsequent self-repairing mechanism are illustrated in Table 4. Figure 14 shows the restoring force curves. Figure 15 shows the crack width measurements for all the tested specimens.

As illustrated in Table 4, for SD-SR1 specimen, a residual crack width of $0.15 \mathrm{~mm}$ was observed and

8 L-Epoxy resin was chosen for self-repairing. For SD-SR2 specimen, with the residual crack width of

$9 \quad$ 0.5mm, L and M-Epoxy resins were chosen. ST-SR1 and ST-SR2 specimens also went through similar combination of epoxy resins. SEA-SR1 and SEA-SR2 specimens showed the residual crack widths of

$110.06 \mathrm{~mm}$ and $0.3 \mathrm{~mm}$ respectively, and both specimens were repaired by L-Epoxy resin injection. To 
Manuscript submitted for possible publication in Smart Materials and Structures

Feasibility of externally activated self-repairing concrete with epoxy injection network and Cu-Al-Mn super-elastic alloy reinforcing bars

by S Pareek, K C Shrestha, Y Suzuki, T Omori, R Kainuma and Y Araki

SEA-SR3, with the residual crack width of $0.5 \mathrm{~mm}$, L and M-Epoxy resins were injected. For ST-SR2 specimen, the residual crack width observed was $1.0 \mathrm{~mm}$, which is comparatively higher among the rest of the specimens.

After accelerated curing for 3 days at $40^{\circ} \mathrm{C}(60 \% \mathrm{RH})$, each of the specimen was reloaded to the pre-defined deformation load level as illustrated in Table 4. Crack repairing of the specimen can be confirmed if new cracks appear at different locations during the reloading process. The cracking patterns for each of the specimens before and after the reloading are shown in Figure 16. All the specimens showed origination of new cracks with the exception of ST-SR2 specimen. It should be noted that ST-SR2 specimen had residual crack width of $1.0 \mathrm{~mm}$ at the end of first loading/unloading cycle, highest among all other test specimens as listed in Table 4.

The restoring force curves in Figure 14 show similar characteristics of the specimens in accordance with the rebars as reported in Section 5.1. SD-SR and ST-SR specimens showed large residual rotation at the end of each loading cycle. SEA-SR specimens showed typical flag shaped hysteresis with small residual rotation, possibly due to yielding of steel rebars in the compression side. Experimentally measured hysteresis loops are compared with the FE and theoretical computations. It should be noted that, FE computations do not include concrete crack repair and hence, the second loading cycle will be applied on the cracked concrete FE model without repair. As illustrated in Figure 14, the FE models and theoretical predictions predicted the strength measurements closely. Here again, there are some discrepancies on the first loading cycle hysteresis, possibly contributed by the loading arrangement as reported earlier. Furthermore, the SEA-SR FE models confirm yielding of top steel rebars for SEA-SR2 and SEA-SR3 specimens, contributing to the residual rotation observed during the tests.

The rate of crack repairing for each of the specimens, by observing the transit time of ultrasonic pulses, as illustrated in Figure 6, at 6 different locations of the specimen, is presented in Figure 17. For all the SEA-SR specimens, the computed rate of crack repairing was above $80 \%$ at all the points of the specimen. This clearly shows that effective self-repairing was attained for all the SEA-SR specimens. The average rate of crack self-repairing for all SEA-SR specimens was $93.5 \%$ with the standard deviation of 6.94\%. For SD-SR1 and SD-SR2 specimens, moderate crack self-repairing was observed, with strong variability in the transit time recorded at different locations as shown in Figure 17. SD-SR specimens showed average rate of crack self-repairing of $80 \%$ with standard deviation of $23 \%$. ST-SR specimens showed poor self-repairing of cracks based on the transit time recorded for both the 
Manuscript submitted for possible publication in Smart Materials and Structures

Feasibility of externally activated self-repairing concrete with epoxy injection network and Cu-Al-Mn super-elastic alloy reinforcing bars

by S Pareek, K C Shrestha, Y Suzuki, T Omori, R Kainuma and Y Araki

10 specimens. An average rate of crack self-repairing for ST-SR specimens was $56.2 \%$ with standard deviation of $20.3 \%$.

The results obtained from the ultrasonic crack detection show a clear superiority of SEA-SR specimens, with effective self-repairing of cracks up to the deformation level of $\theta_{3}=1 / 40 \mathrm{rad}$. SD-SR specimens show moderate crack self-repairing up to the deformation level of $\theta_{2}=1 / 75 \mathrm{rad}$. ST-SR specimens show relatively poor crack self-repairing. More importantly, the self-repairing of cracks by epoxy injection is found effective up to the crack width of $0.5 \mathrm{~mm}$, for all the specimens tested.

Table 4 Details on Test Plan-2 observations

\begin{tabular}{cccccc}
\hline Specimen & $\begin{array}{c}\text { 1st } \\
\text { cycle loading }\end{array}$ & $\begin{array}{c}\text { Residual } \\
\text { crack width }\end{array}$ & Epoxy type & $\begin{array}{c}\text { 2nd } \\
\text { cycle loading }\end{array}$ & $\begin{array}{c}\text { Crack type on } \\
\text { reloading }\end{array}$ \\
\hline SD-SR1 & $1 / 150 \mathrm{rad}$ & $0.15 \mathrm{~mm}$ & $\mathrm{~L}$ & $1 / 75 \mathrm{rad}$ & New crack \\
SD-SR2 & $1 / 75 \mathrm{rad}$ & $0.5 \mathrm{~mm}$ & L \& M & $1 / 40 \mathrm{rad}$ & New crack \\
ST-SR1 & $1 / 150 \mathrm{rad}$ & $0.3 \mathrm{~mm}$ & $\mathrm{~L}$ & $1 / 75 \mathrm{rad}$ & New crack \\
ST-SR2 & $1 / 75 \mathrm{rad}$ & $1.0 \mathrm{~mm}$ & L \& M & $1 / 40 \mathrm{rad}$ & Old crack \\
SEA-SR1 & $1 / 150 \mathrm{rad}$ & $0.06 \mathrm{~mm}$ & $\mathrm{~L}$ & $1 / 75 \mathrm{rad}$ & New crack \\
SEA-SR2 & $1 / 75 \mathrm{rad}$ & $0.3 \mathrm{~mm}$ & $\mathrm{~L}$ & $1 / 40 \mathrm{rad}$ & New crack \\
SEA-SR3 & $1 / 40 \mathrm{rad}$ & $0.5 \mathrm{~mm}$ & L \& M & $1 / 40 \mathrm{rad}$ & New crack \\
\hline
\end{tabular}

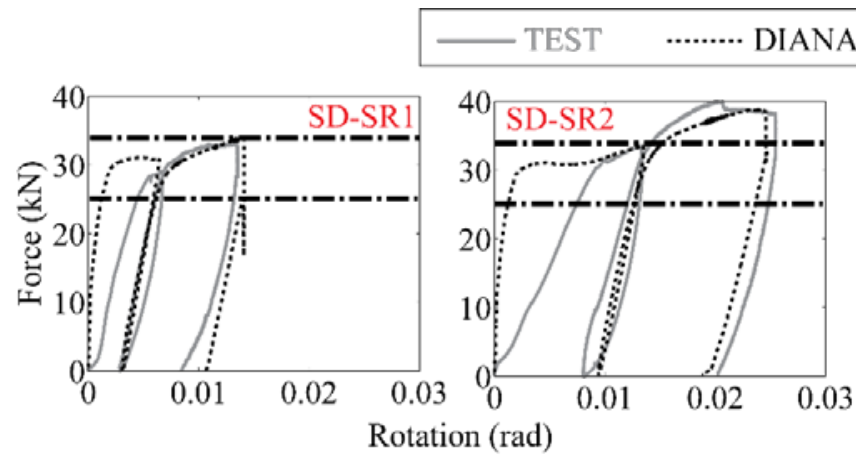

-.-.. Theoretical prediction
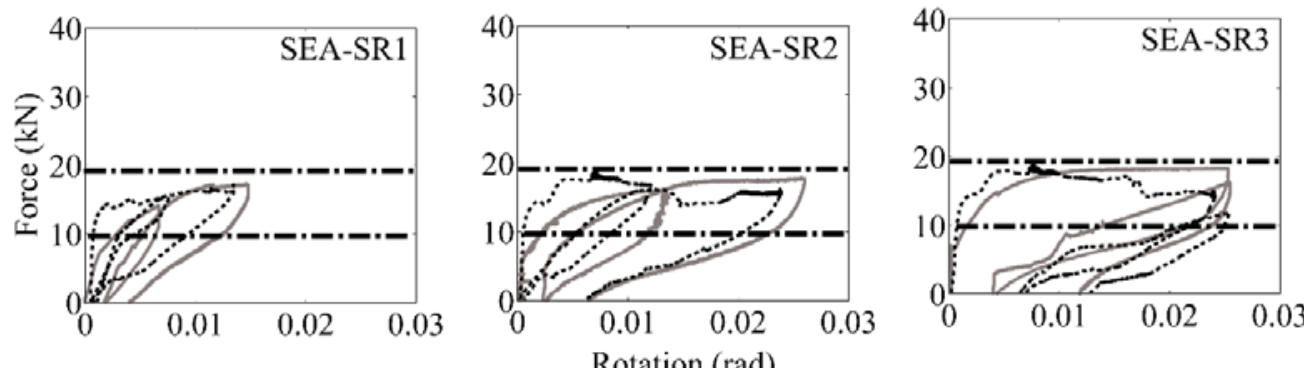

Figure 14. Restoring force curves (first and second cycles) made for SD-SR1, SD-SR2, ST-SR1, ST-SR2, SEA-SR1, 
Manuscript submitted for possible publication in Smart Materials and Structures

Feasibility of externally activated self-repairing concrete with epoxy injection network and Cu-Al-Mn super-elastic alloy reinforcing bars

by S Pareek, K C Shrestha, Y Suzuki, T Omori, R Kainuma and Y Araki

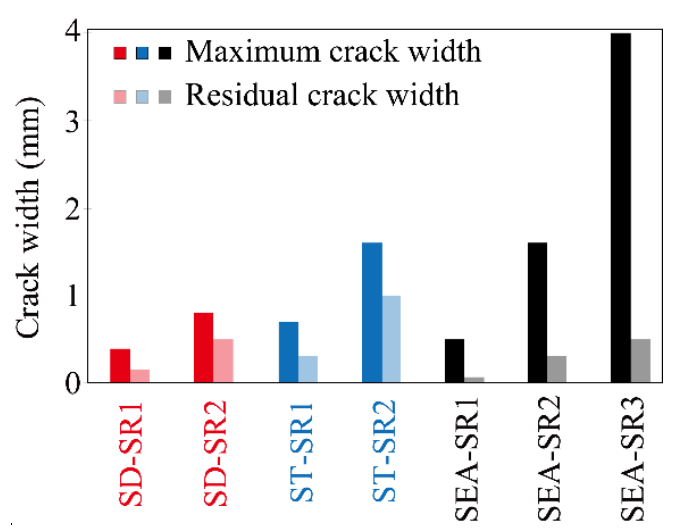

Figure 15. Crack width measurements (first loading/unloading cycle) made for SD-SR1, SD-SR2, ST-SR1, ST-SR2, SEA-SR1, SEA-SR2 and SEA-SR3 specimens.
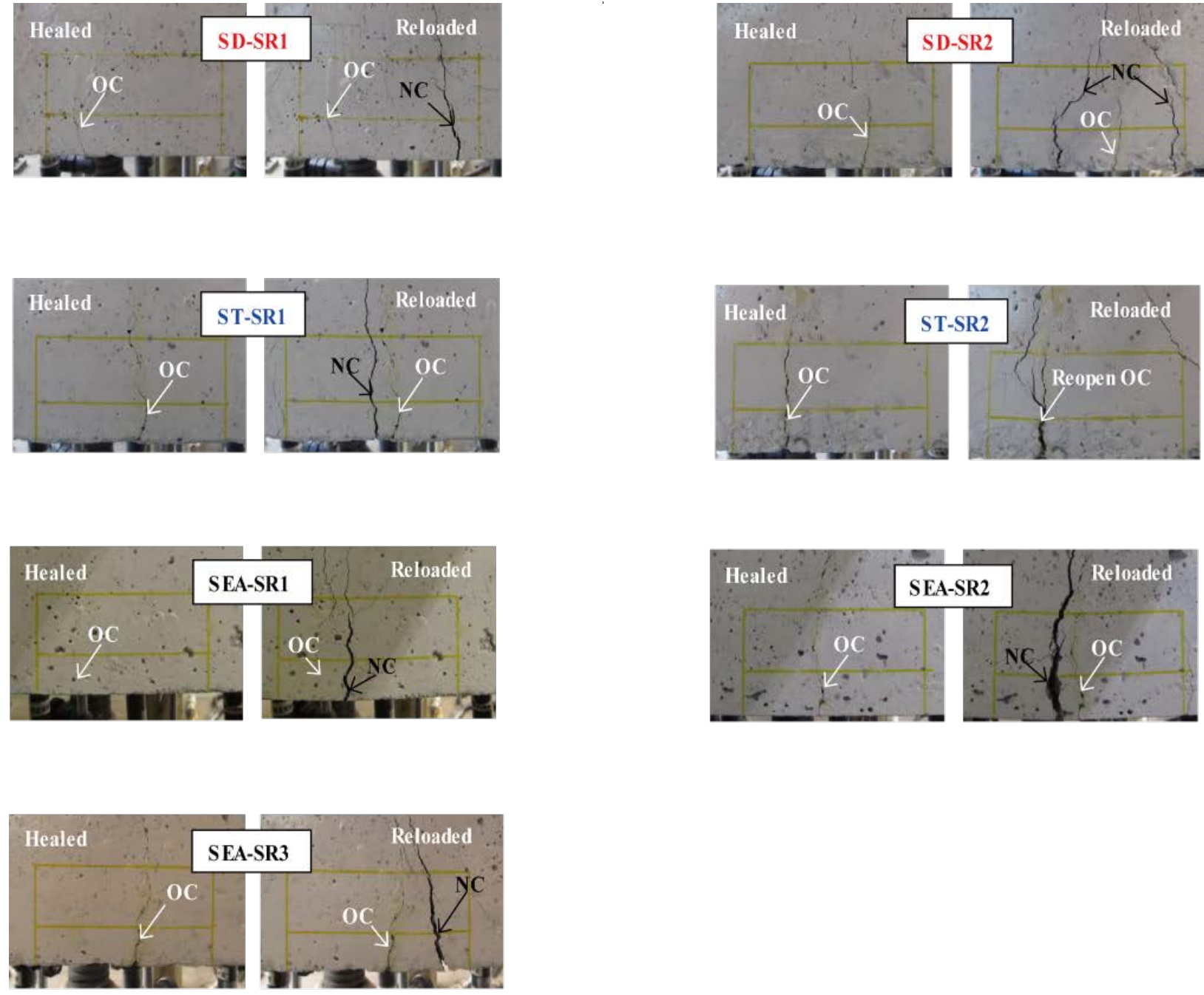

Figure 16. Crack patterns for specimens before and after reloading. 
Manuscript submitted for possible publication in Smart Materials and Structures

Feasibility of externally activated self-repairing concrete with epoxy injection network and Cu-Al-Mn super-elastic alloy reinforcing bars

by S Pareek, K C Shrestha, Y Suzuki, T Omori, R Kainuma and Y Araki

Figure 17. Results on rate of crack self-repairing for all tested specimens.

\section{Conclusions}

Experimental and numerical works have been done to assess the effectiveness of an externally activated self-repairing technique through repeated loading tests of $1 / 3$ scale model of RC beams with the use of cost-effective Cu-based SEA rebars. Comparison on 3 different types of reinforcing bars were made, namely steel deformed rebars, steel threaded rebars, and SEA threaded rebars. New cracks were clearly observed during reloading of the self-repaired specimens for the crack widths up to $0.5 \mathrm{~mm}$ in all the specimens. In ultrasonic tests, nearly perfect repairing was seen up to the crack width of $0.5 \mathrm{~mm}$, for the specimens irrespective of the type of rebars. Due to re-centering capability of the concrete specimen with SEA rebars and its control over the residual crack width, the present technique was effective for at least the rotation angle of 1/40rad., which is much higher than the case of the specimens with steel rebars.

The results reported in this paper are positioned as an initial stage of the research work for developing practical self-repairing concrete. Here, external activation of self-repairing was carried-out manually using syringes for pressurized epoxy injection after the deformation reaches the pre-specified level. Automated monitoring of cracks using sensors and automated epoxy injection through the networks 
Manuscript submitted for possible publication in Smart Materials and Structures

Feasibility of externally activated self-repairing concrete with epoxy injection network and Cu-Al-Mn super-elastic alloy reinforcing bars

by S Pareek, K C Shrestha, Y Suzuki, T Omori, R Kainuma and Y Araki

using some devices will be focused on as a future topic of this work. Furthermore, the effect of any subsequent vibration or deformation during the curing period of epoxy resin in the proposed self-repairing technique requires further study and is also an important subject for future work.

\section{Acknowledgements}

This research was supported by Grant-in-Aid for Scientific Research (B) No. 24360226 provided by Japan Society for the Promotion of Science (JSPS). The SEA bars were provided by Furukawa Techno Material Co. The authors would like to acknowledge the technical assistance of Mr. Yuki Miura of Nihon University in undertaking the experimental works. The authors would also like to acknowledge the anonymous reviewers whose comments and questions led to significant improvement of the paper.

\section{References}

[1] Shrestha K C, Araki Y, Nagae T, Koetaka Y, Suzuki Y, Omori T, Sutou Y, Kainuma R and Ishida K 2013 Feasibility of Cu-Al-Mn superelastic alloy bars as reinforcement elements in concrete beams Smart Mater. Struct. 22025025

[2] Pareek S and Ohira A 2011 A fundamental study on regain of flexural strength of mortars by using a self-repair network system Proc. 3rd International Conf. on Self-Healing Mater., Bath

[3] De Rooij M, Van Tittelboom, K, De Belie N and Schlangen E (Eds.) 2013 Self-healing phenomena in cement based materials State-of-the-art report of RILEM technical committee 221-SHC (Dordrecht Heidelberg New York London: Springer)

[4] Mihashi, Nishiwaki, 2012 Development of engineered self-healing and self-repairing concrete Journal of Advanced Concrete Technology 10 170-84

[5] JCI 2009 JCI-TC075B: Technical committee report on autogenous-healing in cementitious materials (Japan Concrete Institute) (In Japanese)

[6] JCI 2011 JCI-TC091A: Technical committee report on self-healing/repairing technology in cement-based materials (Japan Concrete Institute) (In Japanese)

[7] Nehdi M, Alam M S and Youssef M A 2011 Seismic behavior of repaired superelastic shape memory alloy reinforced concrete beam-column joint Smart Struct. System 5 329-48 
Manuscript submitted for possible publication in Smart Materials and Structures

Feasibility of externally activated self-repairing concrete with epoxy injection network and Cu-Al-Mn super-elastic alloy reinforcing bars

by S Pareek, K C Shrestha, Y Suzuki, T Omori, R Kainuma and Y Araki

[8] Nikopour H and Nehdi M 2011 Shear repair of RC beams using epoxy injection and hybrid external FRP Mater. Struct. 44 1865-77

[9] Li V C and Yang E-H 2008 Self healing in concrete materials Self Healing Materials 161-193

[10] Wu M, Johannesson B and Geiker M 2012 A review: Self-healing in cementitious materials and engineered cementitious composite as a self-healing material Construction and Building Materials 571-583

[11] Dry C 1994 Matrix cracking repair and filling using active and passive modes for smart timed release of chemicals from fibers into cement matrices Smart Mater. Struct. 3 118-123

[12] Dry C and McMillan W 1996 Three-part methylmethacrylate adhesive system as an internal delivery system for smart responsive concrete Smart Mater. Struct. 5 297-300

[13] Saiidi M S and Wang H 2006 Exploratory study of seismic response of concrete columns with shape memory alloys reinforcement ACI Struct. J. 103 436-43

[14] Saiidi M S, Sadrossadat-Zadeh M, Ayoub C and Itani A 2007 Pilot study of behavior of concrete beams reinforced with shape memory alloys J. Mater. Civil Eng. 19 454-61

[15] Youssef M A, Alam M S and Nehdi M 2008 Experimental investigation on the seismic behavior of beam-column joints reinforced with superelastic shape memory alloys J. Earthq. Eng. 12 $1205-22$

[16] Nehdi M, Alam M S and Youssef M A 2010 Development of corrosion-free concrete beam-column joint with adequate seismic energy dissipation Eng. Struct. 32 2518-28

[17] Kuang Y and Ou J 2008 Self-repairing performance of concrete beams strengthened using superelastic SMA wires in combination with adhesives released from hollow fibers Smart Mater. Struct. 17025020

[18] Sutou Y, Omori T, Kainuma R and Ishida K 2003 Effect of grain size and texture on superelasticity of $\mathrm{Cu}-\mathrm{Al}-\mathrm{Mn}$-based shape memory alloys J. Phys. IV 112 511-4

[19] Araki Y, Endo T, Omori T, Sutou Y, Koetaka Y, Kainuma R and Ishida K 2010 Potential of superelastic Cu-Al-Mn alloy bars for seismic applications Earthq. Eng. Struct. Dyn. 40 107-15

[20] Omori T., Kusama T., Kawata S., Ohnuma I., Sutou Y., Araki Y., Ishida K., Kainuma R 2013 
Manuscript submitted for possible publication in Smart Materials and Structures

Feasibility of externally activated self-repairing concrete with epoxy injection network and Cu-Al-Mn super-elastic alloy reinforcing bars

by S Pareek, K C Shrestha, Y Suzuki, T Omori, R Kainuma and Y Araki

Abnormal grain growth induced by cyclic heat treatment Science 341 1500-1502

[21] Shrestha K C, Pareek S, Omori T and Araki Y 2012 Feasibility of self-repair network system in concrete beams with $\mathrm{Cu}-\mathrm{Al}-\mathrm{Mn}$ superelastic alloy bars, Proc. JCI Annual Conference 34 $1438-1443$

[22] Kumada H, Oohira A and Pareek S 2011 A Fundamental Study on Regain of Flexural Strength of

[23] AIJ 2006 Recommendations for practice of crack control in reinforced concrete buildings (Design and Construction), (Architectural Institute of Japan) (In Japanese)

[24] Alam M S, Youssef M A and Nehdi M 2008 Analytical prediction of the seismic behavior of superelastic shape memory alloy reinforced concrete elements Eng. Strct. 30 3399-411

[25] Abdulridha A, Palermo D, Foo S and Vecchio F J 2013 Behavior and modeling of superelastic shape memory alloy reinforced concrete beams Eng. Struct. 49 893-904

13 [26] DIANA 2008 DIANA User's Manual Release 9.3 (Delft: TNO DIANA BV)

14 [27] He W, Wu Y F and Liew K M 2008 A fracture energy based constitutive model for the analysis of reinforced concrete structures under cyclic loading Comput. Meth. Appl. Mech. Eng. 197 4745-62

[28] Monti G and Nuti C 1992 Nonlinear cyclic behavior of reinforcing bar including buckling $J$. Struct. Eng. ASCE 118 3268-84

[29] Christopoulos C, Filiatrault A and Folz B 2002 Seismic response of self-centering hysteretic SDOF systems Earthq. Eng. Struct. Dyn. 31 1131-50

[30] Seo C-Y and Sause R 2005 Ductility demands on self-centering systems under earthquake loading 